\title{
POLÍTICAS PÚBLICAS DE TURISMO SOSTENIBLE: PERSPECTIVA HISPANO BRASILEÑA
}

Felio José Bauzá Martorell ${ }^{1}$

Universidad de las Islas Baleares

\section{RESUMEN}

La promoción y fomento del turismo durante décadas ha desencadenado un fenómeno de masificación turística, con efectos nocivos para la población residente de los territorios turísticos (principalmente la dificultad de acceso a la vivienda), y muy especialmente para los recursos naturales y el medio ambiente. La (imperiosa) necesidad de que las políticas de turismo sean sostenibles está obligando a la gestación de medidas hasta ahora impensables, que pasan por la limitación del número de visitantes en sus distintas manifestaciones. Este artículo se plantea como objetivo fundamental el análisis de las causas de la masificación turística, que pasan por un fomento estrictamente numérico del número de visitantes o el incentivo de la vivienda turística vacacional; asimismo se estudia la repercusión de la masificación en el precio de la vivienda, la expulsión de la población residente, o la generación de conflictos sociales y turismo fobia. La metodología seguida para el presente artículo consiste en un análisis de los cambios sociológicos y antropológicos experimentados principalmente en España (y el resto de Europa) y Brasil, y la revisión de la normativa existente, al objeto de confirmar si sigue siendo útil al fin perseguido, o si por el contrario debe ser objeto de revisión. Como el lector comprobará seguidamente, es este último el resultado alcanzado, siempre desde la perspectiva de conciliar el turismo como actividad económica, y la preservación del medio ambiente. En conclusión se sugiere la implementación de políticas turísticas medio ambientalmente

1 Doctor de Derecho Público por la Universitat de les Illes Balears (UIB). Máster de Urbanismo y Ordenación del Territorio por la UIB. Licenciado en Derecho por la Universidad Pontificia de Comillas (ICADE). Profesor contratado doctor en Derecho Público en la UIB. ORCID: https://orcid. org/0000-0003-2526-3619 / e-mail: ffj.bauza@uib.es 
sostenibles desde la vertiente de la ordenación del territorio, la tributación, la limitación del alquiler turístico y del acceso a espacios de dominio público, entre otros.

Palabras clave: masificación; medio ambiente; sistema de cupos; turismo.

\section{PUBLIC POLICIES OF SUSTAINABLE TOURISM: BRAZILIAN HISPANIC PERSPECTIVE}

\section{ABSTRACT}

Promotion of tourism for decades has triggered a phenomenon of tourist overcrowding, with harmful effects for the resident population of the tourist territories (mainly the difficulty of access to housing), and especially for natural resources and the environment. The (imperative) need for tourism policies to be sustainable is forcing the gestation of measures so far unthinkable, which go through the limitation of the number of visitors in their different manifestations. This article sets out as a fundamental objective the analysis of the causes of tourist overcrowding, which go through a strictly numerical promotion of the number of visitors or the incentive of tourist holiday housing; Likewise, the impact of the massification on the price of housing, the expulsion of the resident population, or the generation of social conflicts and phobic tourism is studied. The methodology followed for this article consists of an analysis of the sociological and anthropological changes experienced mainly in Spain (and the rest of Europe) and Brazil, and the revision of the existing regulations, in order to confirm whether it is still useful for the purpose pursued., or if on the contrary it should be subject to review. As the reader will check next, the latter is the result achieved, always from the perspective of reconciling tourism as an economic activity, and the preservation of the environment. In conclusion, the implementation of environmentally sustainable tourism policies is suggested from the aspect of land management, taxation, the limitation of tourist rental and access to public domain spaces, among others.

Keywords: environment; massification; quota system; tourism. 


\section{INTRODUCCION}

El turismo constituye fundamentalmente una actividad económica, que representa el 8'1 \% del PIB de Brasil y el 12\% del mismo índice en España. En términos de empleo el turismo representa el 3'5\% de la población activa de Brasil y el 14\% de la española.

Pero la económica no es la dimensión exclusiva del turismo, que presenta otros componentes de necesaria protección por parte de los poderes públicos: el patrimonio histórico, el deporte, la cultura, las celebraciones religiosas como la Semana Santa... y todo ello sin despreciar la vertiente jurídica (contratación turística, alojamiento, transporte, relaciones jurídicas a distancia a través de medios técnicos) (BAUZÁ MARTORELL, 2014).

De ahí que la intervención administrativa en materia de turismo haya sido tradicionalmente a través de la actividad de fomento, mediante políticas de desestacionalización y diversificación de la oferta turística con el objetivo de incrementar un año tras otro el número de visitantes en cualquier país.

En este sentido la construcción de infraestructuras turísticas (palacios de congresos, instalaciones de invierno, pistas de eventos deportivos...), junto a medidas de incentivos fiscales y subvenciones (turismo rural) hayan sido una constante en las últimas décadas.

Como también lo han sido actuaciones impulsoras del turismo de cruceros (inversiones en infraestructuras portuarias), la promoción del turismo a través de la creación de oficinas de turismo en el exterior ${ }^{2}$, o la regulación de la vivienda turística vacacional (ENCARNACIÓN; PALOP; GOLOBARDES, 2018; GARCÍA SAURA, 2019).

En consecuencia el primer dato a tener en cuenta por lo que respecta a las políticas de turismo es el del fomento del turismo, teniendo en cuenta fundamentalmente el referente de su contribución al crecimiento económico y la generación de empleo.

En consecuencia debemos partir como hipótesis de trabajo el crecimiento del turismo considerado como una actividad meramente

2 En España TURESPAÑA es el organismo público, adscrito al Ministerio de Industria, Comercio y Turismo a través de la Secretaría de Estado de Turismo, responsable del marketing de España como destino de viajes en el mundo. Turespaña despliega su actividad en el exterior a través de una red de 33 Consejerías de Turismo, que suponen un activo estratégico del sector turístico español, por su función de interfaz con el sector profesional emisor, los prescriptores de opinión y el viajero en origen. Organizadas funcionalmente en 8 áreas geográficas, coincidentes, en buena medida, con distintas tipologías de mercados, estas Consejerías de Turismo operan en 47 mercados turísticos emisores, de acuerdo con su respectivo Plan Operativo Anual, en el que se incluyen las actividades a realizar en colaboración con las Comunidades Autónomas y otras entidades públicas de promoción. 
económica, para -a partir de esta premisa- analizar de qué forma el ordenamiento jurídico puede poner límite al turismo, con las miras puestas a la protección ambiental.

\section{RESULTADOS DEL CRECIMIENTO ILIMITADO DEL TURISMO}

La apuesta decidida por el turismo ha desencadenado en Europa unos resultados incompatibles con la sostenibilidad, principalmente en forma de masificación turística, de grandes aglomeraciones y afluencias de visitantes, cuya presencia en tales magnitudes afecta a la vida de la población residente.

En efecto pueden enumerarse las siguientes distorsiones derivadas del crecimiento ilimitado del turismo:

\subsection{Masificación}

Un dato incuestionable de los últimos años en materia turística consiste en la masificación de destinos turísticos, que se explica por el abaratamiento del coste del transporte y del alojamiento turístico, así como por el uso de medios técnicos.

En efecto en Europa existen ciudades verdaderamente saturadas por el turismo, como Venecia, Dubrovnik, o Amsterdam, entre otras. Con carácter general la masificación es un hecho real, que afecta a los recursos naturales de un territorio (agua potable, energía, generación de residuos...), al tiempo que convierte los espacios en intransitables.

La afluencia de turistas, contemplada desde un prisma estrictamente económico, puede considerarse un resultado ventajoso; sin embargo, si se confronta con la variable medio ambiental, es fácil colegir que no se puede admitir esta deriva del turismo mal entendido, so pena de generar desajustes en términos sociales y medio ambientales.

Como decimos, los medios técnicos tiene mucho que ver con la masificación, toda vez han contribuido a una transformación radical de la relación jurídica entre la oferta y la demanda turística, que ya no necesita la mediación (agencias de viajes), sino que el usuario de servicios turísticos contrata directamente con el ofertante, conoce las opiniones y valoraciones de otros usuarios, y a través de un dispositivo móvil organiza un viaje y se desplaza a cualquier lugar (MARTÍNEZ NADAL, 2019). 
Fuera de Europa la situación es igual de preocupante. Los medios de comunicación publican con frecuencia el cierre de playas por mor de la masificación turística: las Islas Feroe en Dinamarca, después de un crecimiento del 10 por 100 del número de visitantes; el campamento base del Everest, por la gran cantidad de basura acumulada; la isla de Boracay en Filipinas estuvo cerrada durante seis meses en 2018 al ser calificada como "fosa séptica"; la playa de Maya Bay en Tailandia, famosa por aparecer en un largometraje del actor Leonardo Di Caprio, se encuentra cerrada entre 2018 y 2021 para que los arrecifes de coral puedan recuperarse ${ }^{3}$, y así un largo etcétera de casos y supuestos, que evidencian que la aglomeración de visitantes -lejos de ser una amenaza potencial- constituye un daño real y efectivo para el ecosistema y el medio natural.

\subsection{Vivienda turística y precio de la vivienda}

En los últimos años y al amparo de las plataformas digitales y portales de internet, el sector turístico ha descubierto una modalidad de alojamiento distinta del tradicional hotelero y extra hotelero (apartamentos turísticos, bungalows, villas, turismo rural y campamentos de turismo). Nos referimos a la vivienda turística, que consiste en el alquiler de una vivienda residencial por períodos de corta duración (BAUZÁ MARTORELL, 2018).

Esta modalidad de alojamiento no hubiera sido posible sin las plataformas de economía colaborativa (las que relacionan a propietarios que permutan estancias en viviendas) o en los portales de mediación de viviendas, que en cualquier caso permiten la contratación de una estancia turística en una vivienda, con la ventaja de conocer la opinión de otros usuarios previos.

La vivienda turística ha permitido un crecimiento exponencial del número de visitantes, a los que se ve por los centros de las ciudades con una maleta buscando una dirección postal. Al mismo tiempo ha convertido en empresarios turísticos a los propietarios de tales viviendas, que practican una actividad económica sometida a tributación y a un control de calidad de los servicios que prestan.

Sin perjuicio de retos y desafíos jurídicos de la vivienda turística, como es el caso de la superposición del uso residencial y el uso turístico en un mismo inmueble 4 , lo cierto y verdad es que esta modalidad de alojamiento 
turístico conlleva asociado la masificación a la que nos hemos referido, al tiempo que un incremento del precio de la vivienda.

En efecto el propietario de una vivienda obtiene mayores rentas alquilando el inmueble turísticamente que de forma anual con arreglo al régimen de arrendamiento urbano. Ello significa que el parque de viviendas ofertadas en alquiler convencional se restringe notablemente y que el acceso a la vivienda se torna muy costoso, en ocasiones imposible para una economía familiar dentro de los umbrales de la normalidad.

En algunos territorios limitados (nos referimos a la isla española de Ibiza), en los que la temporada turística conlleva el desplazamiento de trabajadores privados y servidores públicos procedentes del territorio continental, se llegue a hablar de situaciones de emergencia habitacional, en los que se dan ciertos episodios no exentos de hilaridad (alquiler de balcones y terrazas, de vehículos en la vía pública para pernoctar...).

El incremento del precio de la vivienda se convierte así en una consecuencia del crecimiento deslavazado del turismo, y en una ineficacia del mercado de la vivienda.

\subsection{Expulsión de la población residente}

Una consecuencia inevitable del incremento del precio de la vivienda consiste en la expulsión de la población residente de los centros históricos de las ciudades, donde se concentran las viviendas turísticas.

Esta circunstancia se da por un doble motivo: bien porque los propietarios se desplazan a otras zonas con tal de alquilar sus viviendas y obtener generosas rentas; o bien porque la población residente en régimen de alquiler no puede afrontar las rentas que los propietarios les exigen en comparación con el alquiler turístico.

Sea como fuere en cualquier caso los centros de las ciudades quedan despoblados de población residente, y se convierten en zonas netamente turísticas (en algún momento se las ha llegado de calificar como parques temáticos). Desaparecen los comercios tradicionales, que dan paso a

municipal ha previsto las infraestructuras necesarias para una población que residen con carácter de permanencia (aparcamientos, recogida de residuos, suministro de agua potable, energía eléctrica...). Introducir el uso turístico en un inmueble (piénsese en la propiedad horizontal) o en una zona en la que el ordenamiento detallado prevé el uso residencial, supone la generación de una disfunción (los horarios de un turista distan mucho de la población residente, sujeta a un horario de trabajo y a unas horas de descanso). De ahí que este problema no se halle resuelto más allá de algún pronunciamiento judicial aislado (BAUZÁ MARTORELL, 2018). 
establecimientos franquiciados y en general la población que habita estas zonas es meramente transeúnte, en ningún caso permanente 5 .

\subsection{Reestructuración de la economía del turismo}

Las plataformas digitales han ocasionado cambios sustanciales en el modelo turístico, que ha pasado del sistema convencional de la mediación a una relación directa entre el ofertante y el demandante de servicios turísticos.

En consonancia con esta relación jurídica, la mediación turística ha perdido toda su razón de ser, de manera que ya no se aprecian agencias de viaje minoristas, sino que en cualquier caso han tenido que adaptarse al nuevo escenario de los medios técnicos, ya sean OTAs (acrónimo de On Line Travel Agencies) (FLECHA BARRIO, 2016), o centrales electrónicas de reservas turísticas (BAUZÁ MARTORELL, 2014). A nadie escapa que esta nueva forma de contratación entre ausentes plantea retos y desafíos jurídicos para los que el derecho positivo vigente no siempre otorga soluciones y que en consecuencia necesita adaptación (FLAQUER RIUTORD, 2015).

Otra actividad económica del sector turístico que pierde peso específico en el conjunto del sistema es de los guías de turismo, que ven limitada su intervención por cuanto el turista-amparado en los medios técnicos- se convierte en autónomo y no necesita de tales servicios.

En efecto, ya sea por la cantidad de información que circula por la red en cuanto a rutas, lugares de interés, explicación histórica, horarios de visita, precios y tarifas..., o bien por las valoraciones vertidas por otros usuarios, los medios digitales sustituyen por completo al guía turístico, de manera que el turismo ya no se organiza tanto por grupos perfectamente delimitados en torno al guía, sino que los turistas acceden individualmente (aunque sea en masa en su conjunto) a los espacios de interés (MUNAR BERNAT, 2008).

\subsection{Reestructuración de la administración turística}

Los medios técnicos, al tiempo que han contribuido directamente a la masificación de visitantes, han puesto a disposición del turista nuevas

5 El documental El síndrome de Venecia explica con claridad esta circunstancia. Vid. https://www. youtube.com/watch?v=WVTEfMLBW4s. Fecha de consulta: 12 de octubre de 2019. 
formas de control de la actividad turística, que en ocasiones resultan más efectivas y temidas que cualquier sanción administrativa.

En efecto la sanción meramente económica ha relativizado sus efectos en el tráfico comercial; a pesar de que las Leyes de Procedimiento Administrativo con carácter general prevean que la infracción no puede resultar rentable (no puede ser inferior el montante de la sanción económica al beneficio que genera la infracción) (NIETO, 2012), lo cierto y verdad es que el infractor afronta la multa con la idea de que la infracción sólo tiene efectos en la cuenta de resultados y que en cualquier caso el número de infracciones cometidas compensa la sanción recibida.

En cambio la publicidad de la infracción, toda vez que afecta a los potenciales clientes, puede resultar más problemática; de ahí que las leyes de procedimiento -incluso la legislación sectorial turística- prevean registros públicos de infracciones, que cualquier ciudadano puede consultar y así hacerse una idea del grado de calidad de los servicios turísticos que ofrece un operador ${ }^{6}$.

Dada la realidad sociológica actual, los clientes no siempre consultan un registro administrativo de sanciones turísticas, y sí en cambio tienen a su disposición los comentarios y opiniones que otros clientes anteriores vierten en las redes sociales, o en las mismas plataformas técnicas de mediación turística.

Estos medios resultan en consecuencia mucho más efectivos que la sanción administrativa, porque se conocen en tiempo real en cualquier parte del mundo y pueden derivar en un descenso notable de la demanda de servicios turísticos.

Un ejemplo puntual de lo que venimos diciendo es la publicación en las redes sociales de la queja de unos usuarios en un restaurante en una playa de Formentera. Al recibir la cuenta, que era astronómica, tenían la opción de solicitar el libro de reclamaciones, con la salvedad de que no se puede formalizar una reclamación por motivos de precio, si no se abona el mismo. Una de las hojas del libro de reclamaciones se hubiera dirigido a la Administración Turística, que hubiera iniciado un procedimiento administrativo que hubiera durado mucho tiempo, sin perjuicio de los recursos

6 El art. 115 de la Ley 8/2012, de 19 de julio, del Turismo de las Islas Baleares, prevé la anotación de sanciones definitivas en el registro insular de empresas, actividades y establecimientos turísticos correspondiente. Las anotaciones se cancelan de oficio o a instancia de parte transcurridos uno, dos o tres años, según se trate de sanciones por infracciones leves, graves o muy graves, desde su imposición con carácter definitivo o cuando la resolución sancionadora sea anulada por una sentencia firme en vía contencioso- administrativa. El registro tiene obligación de expedir certificado de las sanciones anotadas a las personas interesadas que lo soliciten (BAUZÁ MARTORELL, 2017, p. 139). 
administrativos y judiciales a que hubiera dado lugar. En definitiva, el procedimiento se hubiera perdido en un limbo.

En cambio los usuarios decidieron publicar en twiter una fotografía de la factura, con el título de Tourist trap, trampa para turistas. El mensaje circuló a velocidad de vértigo por cuanto tuvo miles de visitas y retwits, al tiempo que apareció publicado en portada de la prensa local.

Por ello la Administración Turística se ve obligada a adaptar sus fórmulas de control sobre la actividad turística, debiendo estar pendiente lógicamente de los comentarios y opiniones que se vierten en las redes, depurando asimismo los comentarios objetivos de las opiniones meramente subjetivas, que en ocasiones persiguen dañar la reputación ajena de otros competidores del sector (MARTÍNEZ NADAL, 2015).

Asimismo y sin perjuicio de lo que diremos en materia de vivienda turística vacacional, la Administración sólo puede ejercer un control sobre la oferta de vivienda turística a través de páginas de internet.

En consecuencia no podemos dejar de afirmar que los medios técnicos obligan a reestructurar a la Administración Turística, que ya no puede operar exclusivamente con medios convencionales.

\subsection{Conflictos sociales}

La masificación turística genera evidentes conflictos sociales. Donde hay hacinamiento igualmente se encuentran problemas de convivencia como consecuencia del consumo de unos recursos escasos y de una saturación de los servicios públicos, que rebajan su calidad y aumentan los tiempos de espera.

Uno de estos conflictos, al que ya nos hemos referido, consiste en la superposición de usos residencial y turístico en un mismo inmueble, que genera los inconvenientes de mezclar dos estilos muy distintos: uno temporal y transitorio (turístico), y otro permanente y estable (residencial). Ni qué decir tiene que los horarios de uno y otro son también muy distintos, siendo así que en el primer caso la emisión de ruidos puede darse cuando para los demás existe un descanso previo a la jornada laboral.

A mayor abundamiento la masificación atrae a los amigos de lo ajeno, incrementándose el índice de criminalidad por hurtos y robos hacia una población, la visitante, que puede llevar dinero en efectivo en carteras y bolsos.

En este el caso antiguo de muchas ciudades europeas sufre estos 
problemas de convivencia, con exteriorización de protestas en forma de derecho al descanso y eslóganes como "la ciudad para quien la habita"... y un largo etcétera.

\subsection{Turismo fobia}

Un estadio adicional a los problemas de convivencia es la turismo fobia, entendida como manifestación de rechazo de plano contra el turismo, con actuaciones que van desde pintadas en fachadas hasta la exhibición de mensajes en puertos y aeropuertos contrarios al turismo, cuando no la realización de actos vandálicos que generan molestia e incomodidad al visitante.

Ciertamente la turismo fobia no puede ser objeto de relativización en primer lugar por una cuestión elemental de cortesía, sin olvidar la contribución del turismo al PIB que hemos comentado supra (HUETE; MANTECÓN, 2018; MILANO, 2018).

En cualquier caso constituye un dato indicativo de que, pese a la crítica sin paliativos a las expresiones de odio al turismo, la masificación está causando incomodidad a la población residente.

\section{POLÍTICAS DE TURISMO SOSTENIBLE}

Los resultados de un crecimiento ilimitado del turismo exigen la elaboración y diseño de políticas turísticas en clave de sostenibilidad, convirtiéndose así el medio ambiente en un elemento transversal de cualquier política pública.

En este sentido el crecimiento económico, o es sostenible, o no será. No existe alternativa. Por ello los poderes públicos en Europa han comenzado a aplicar medidas correctoras al fomento del turismo, que podemos enumerar en los siguientes términos:

\subsection{Urbanismo y ordenación del territorio: capacidad de carga}

Con carácter general en urbanismo y ordenación del territorio la capacidad de carga se define como el número potencial de personas que un determinado espacio o lugar puede albergar, en función de parámetros urbanísticos, ambientales, paisajísticos, infraestructuras... 
Las distintas leyes autonómicas del suelo ${ }^{7}$ y su normativa complementaria vienen introduciendo parámetros e indicadores en materia de capacidad de carga, como límite general al territorio. Los indicadores particulares en materia turística forman parte de este concepto de capacidad de carga, y persiguen una armonización de la densidad de población residencial con la población visitante, en consonancia a su vez con vectores medio ambientales y la disponibilidad de recursos (agua potable, energía eléctrica y gas, recogida de residuos... $)^{8}$.

La ordenación del territorio se concibe en las distintas Comunidades Autónomas mediante planes territoriales generales y planes directores sectoriales. Entre estos últimos los planes en materia de turismo establecen la capacidad de carga y los límites máximos de la población visitantes. En consecuencia una primera limitación del turismo pasa por estos planes directores sectoriales (BLASCO ESTEVE, 2010).

Los territorios insulares son especialmente sensibles a esta problemática, por cuanto combinan la afluencia turística y las limitaciones territoriales. En el caso de Canarias la Ley 19/2003, de 14 de abril, por la que se aprueban las Directrices de Ordenación General y las Directrices de Ordenación del Turismo de Canarias, contempla de manera expresa la normativa de las directrices de ordenación del turismo de Canarias, en cuyo Capítulo IV regula las condiciones de crecimiento.

Entre los objetivos de estas limitaciones o restricciones, la Directriz 24 justifica el crecimiento selectivo a partir de la creación de nuevos productos cualificados, que diversifiquen la oferta, y que tengan la capacidad de innovar el mercado, atraer otros segmentos de demanda, competir con otros destinos, y contribuir al crecimiento de la economía local y del archipiélago.

Al mismo tiempo la Ley es muy clara a la hora de determinar que la necesidad de ordenar y dimensionar el crecimiento alojativo parte de la exigencia de reducir las afecciones ambientales y territoriales, directas e inducidas, sobre un medio frágil, así como de atemperar el crecimiento a la capacidad de absorción de la sociedad local y la disponibilidad de las infraestructuras y servicios, y de atender al carácter estratégico y prioritario que las presentes Directrices otorgan a la renovación de la planta turística existente, por su mayor grado de sostenibilidad, en tanto que constituye una reutilización eficiente del patrimonio urbano e inmobiliario existentes.

7 Sobre los efectos de la Sentencia del Tribunal Constitucional 61/1997, vid. Fernández (1997).

8 Sobre la capacidad de carga en materia urbanística y turística, vid. Salom Parets (2017). 
A continuación la Directriz 25 se refiere de manera expresa a la capacidad de carga y entiende que toda decisión de transformación por la urbanización del suelo con destino turístico requiere ser establecida y fundamentada técnicamente en la capacidad de carga de la zona turística afectada, entendida como el conjunto de factores que permiten el uso turístico de una zona sin un declive inaceptable de la experiencia obtenida por los visitantes, una excesiva presión sobre los recursos turísticos de la misma, una alteración ecológica sobre la sociedad residente, y disponiendo de los equipamientos, servicios e infraestructuras generales precisos para el desarrollo de la actividad y de la población de servicios que demande. Esta capacidad habrá de ser considerada y analizada por el planeamiento urbanístico en cuanto factor determinante de la sectorización la sectorización de suelo con destino turístico. Todo ello bajo los criterios de capacidad global de carga turística y los criterios específicos determinados por el planeamiento insular.

La determinación de la capacidad de carga integra un documento autónomo dentro de los instrumentos de planeamiento, y se fundamenta, al menos, en los siguientes factores relevantes:

a) Capacidad ecológica, que identificará y valorará los cambios que previsiblemente haya de producir en los ecosistemas la implantación de la actividad turística de que se trate.

b) Capacidad social, que analizará los efectos sobre la población residente, sobre sus condiciones urbanas, habitacionales, de mercado de trabajo y de entorno cultural, así como su afección a los servicios educativos, sanitarios y de bienestar social disponibles.

c) Capacidad paisajística, definida como la potencialidad del paisaje para asumir las actuaciones previstas sin alteración de sus rasgos y elementos característicos.

d) Capacidad de las infraestructuras de accesibilidad y otras existentes para atender el funcionamiento y abastecimiento del ámbito, y posibilidad de absorción de los impactos que se deduzcan de la dotación o ampliación de dichas infraestructuras.

e) Capacidad del mercado, considerando el crecimiento potencial de la demanda frente a la nueva oferta, con el fin de evitar que la generación de desequilibrios entre oferta y demanda deteriore la competitividad del destino y de los operadores.

f) Disponibilidad de recursos tecnológicos, profesionales y laborales necesarios para las fases de construcción y explotación de los 
establecimientos turísticos que se prevean, estimada bajo la hipótesis de aplicar medidas y sistemas adecuados a la conservación del medio ambiente, el ahorro de energía y de agua, y la correcta gestión de los residuos.

g) Disponibilidad de recursos turísticos, evaluados en relación con los productos turísticos previstos, fundamentada en un inventario valorado, destinado a estimar la orientación turística del ámbito y la correspondencia entre recursos, productos turísticos, tipo de demanda y actividades turísticas propuestas.

h) Afección a recursos naturales existentes en los ámbitos propuestos para la actividad urbanística, y en su entorno de influencia ambiental, paisajística y funcional, fundamentada en un inventario y valoración de los recursos y en la previsión de las medidas para su conservación.

Para la valoración de los recursos naturales implicados en la actuación, se considerarán en todo caso como elementos sensibles, los siguientes:

1. Los espacios litorales, cuya extensión a este efecto de protección se establece como la franja costera de 500 metros de anchura, medida desde la ribera del mar.

2. Los relieves y horizontes definidores de los paisajes característicos de cada isla.

3. Las formaciones orográficas y escenográficas naturales características, como los acantilados, barrancos, lomos, conos volcánicos y calderas, entre otras.

4. Los suelos agrícolas productivos, y los que caracterizan la imagen del territorio.

5. La vegetación y, especialmente, el arbolado.

Por último y de manera concreta en materia de límites del crecimiento, la Directriz 26 se refiere a los instrumentos de planeamiento municipal, a los que permite igualmente introducir restricciones al crecimiento turístico. Así, la Norma obliga al planeamiento insular a declarar agotada la capacidad de carga de aquellos ámbitos territoriales en los que así se deduzca del análisis de los factores relacionados en la Directriz anterior, pudiendo afectar dicha declaración a zonas o núcleos concretos de una isla o a la totalidad de la misma. Los efectos de la declaración serán los siguientes:

a) En el ámbito declarado, no podrá aumentar el número de plazas turísticas sobre la oferta existente.

b) En las zonas turísticas incluidas dentro del ámbito declarado, no podrá aumentar el número de plazas residenciales, salvo expresa previsión en contrario del plan insular, debidamente justificada. 
En particular, el planeamiento insular debe justificar la previsión de crecimiento alojativo turístico que el mismo establezca, en relación con la existencia material o dotación financiera para la ejecución de infraestructuras y servicios generales suficientes para cubrir las necesidades de la población residente y turista existentes, como de la generada por el crecimiento turístico previsto, requiriéndose informe de las administraciones competentes. En todo caso, la disponibilidad y capacidad de los servicios de sanidad y educación públicas para el incremento de demanda previsto, será un factor limitante para su desarrollo.

\subsection{Tributación: tasa turística}

La tributación de la estancia turística es un medio disuasorio para la visita de espacios turísticos. En la teoría económica los precios siempre han sido un factor corrector de la demanda.

No en vano el "Estudio sobre la regulación de las viviendas de uso turístico en España", elaborado por la Comisión Nacional de los Mercados y la Competencia de España en fecha 19 de julio de 2018, a la hora de valorar las restricciones por zonas o barrios a las viviendas de uso turístico, considera expresamente que "un instrumento más proporcionado y menos distorsionador de la competencia que la zonificación para internalizar el coste de las externalidades negativas derivadas de la congestión en algunas zonas sería la intervención mediante un impuesto o tasa sobre la estancia en alojamientos turísticos, sin diferenciación del tipo de alojamiento" .

En España sólo dos Comunidades Autónomas han hecho acopio de este tributo: Baleares y Cataluña.

Centrándonos en la primera y sin perjuicio de antecedentes remotos (BAUZÁ MARTORELL, 2019), la regulación vigente del tributo a día de hoy se concreta en la Ley 2/2016, de 30 de marzo, del Impuesto sobre estancias turísticas en las Islas Baleares, y de medidas de impulso del turismo sostenible. La Ley fue desarrollada por el Decreto 35/2016, de 23 de junio, por el que se desarrolla la Ley del impuesto sobre estancias turísticas y de medidas de impulso del turismo sostenible.

La Ley 2/2016 configura el hecho imponible del tributo las estancias, por días o fracciones, con o sin pernoctación, que los contribuyentes realicen en las Illes Balears en los siguientes establecimientos turísticos: 
a) Los establecimientos de alojamiento hotelero, eso es, los hoteles, los hoteles de ciudad, los hoteles apartamentos y los alojamientos de turismo de interior.

b) Los apartamentos turísticos.

c) Las diversas clases de alojamientos de turismo rural, eso es, los hoteles rurales y los agroturismos.

d) Los albergues y los refugios.

e) Las hospederías.

f) Los establecimientos explotados por las empresas turístico-residenciales, excepto con respecto a las unidades de alojamiento residencial.

g) Los hostales, los hostales-residencia, las pensiones, las posadas, las casas de huéspedes y los campamentos de turismo o campings.

h) Las viviendas turísticas de vacaciones, las viviendas objeto de comercialización de estancias turísticas y las viviendas objeto de comercialización turística susceptibles de inscripción de acuerdo con las leyes que las regulan.

i) El resto de establecimientos y viviendas a los que la normativa autonómica otorga la calificación de turísticos.

j) Las viviendas objeto de comercialización turística que no cumplan con los requisitos establecidos para ello en la normativa autonómica y que, por lo tanto, no sean susceptibles de inscripción de acuerdo con la legislación turística vigente.

k) Las embarcaciones de crucero turístico cuando realicen escala en un puerto de las Illes Balears. De acuerdo con ello, no se incluyen los inicios ni las llegadas de los cruceros con salida o destino final en las Illes Balears.

Entre las principales novedades de la regulación que opera esta ley consiste en la inclusión en el hecho imponible a los cruceros, extremo que fue objeto de requerimiento por parte de la Administración General del Estado.

Por lo demás, la disposición final tercera de la Ley 13/2017, de 29 de diciembre, de Presupuestos Generales de la Comunidad Autónoma de las Illes Balears para el año 2018, incrementó un 100 por 100 la cuota tributaria, fijándose con carácter general en los cuatro euros diarios por persona y día.

El destino de los fondos recaudados con cargo a este impuesto consiste en la preservación del medio ambiente. Así, la Ley crea el fondo para 
favorecer el turismo sostenible como instrumento de financiación de los proyectos que se aprueben, y a fin de impulsar un turismo sostenible, responsable y de calidad en el archipiélago de las Illes Balears. Este fondo se nutre de la recaudación total del impuesto sobre estancias turísticas en las Illes Balears.

Los recursos de dicho fondo se destinan a financiar, total o parcialmente, inversiones y otros gastos que, en ejecución de los proyectos que se aprueben, se destinen a las siguientes actuaciones:

a) Protección, preservación, modernización y recuperación del medio natural, rural, agrario y marino.

b) Fomento de la desestacionalización, creación y activación de productos turísticos practicables en temporada baja, y promoción del turismo sostenible y de temporada baja.

c) Recuperación y rehabilitación del patrimonio histórico y cultural.

d) Impulso de proyectos de investigación científica, desarrollo e innovación tecnológica $(\mathrm{I}+\mathrm{D}+\mathrm{i})$ que contribuyan a la diversificación económica, la lucha contra el cambio climático o relacionados con el ámbito turístico.

e) Mejora de la formación y la calidad del empleo. Fomento de la ocupación en temporada baja.

f) Actuaciones en políticas de vivienda destinadas a fomentar el acceso a la vivienda, y especialmente el alquiler social, con criterios de sostenibilidad energética.

En el conjunto de estas actuaciones, se priorizan los proyectos de carácter medioambiental. En todo caso, los proyectos que se aprueben deben ser sostenibles desde el punto de vista ambiental, social y económico?.

\subsection{Limitación del alquiler turístico}

Con carácter general el alquiler turístico ha sido objeto de regulación con la intención del legislador de limitar esta práctica, por los problemas que hemos analizado anteriormente.

La limitación del alquiler turístico no resulta una tarea sencilla, por cuanto se topa con la prohibición de las prácticas restrictivas a la competencia.

En efecto en España la Comisión Nacional de los Mercados y la

9 Para comprender este tributo, vid. el análisis que realiza in extenso (FERNÁNDEZ GONZÁLEZ, 2017). 
Competencia en su Estudio 3/2018, de 19 de julio de 2018 llama la atención en el sentido de que las limitaciones normativas no pueden traducirse en una discriminación de las viviendas turísticas respecto del alojamiento hotelero, sino que deben estar especialmente motivadas.

En este sentido no son pocas las Sentencias del Tribunal Supremo que por un lado confirman que determinadas limitaciones son conforme a Derecho por no ser discriminatorias, o bien anulan preceptos concretos de normas que limitaban el alquiler turístico sin fundamentación objetiva alguna. Nos referimos a la Sentencia del Tribunal Supremo 1237/2019, de 24 de septiembre de 2019 (rec. 2861/2018), sobre la normativa de la Comunidad Castilla y León, la de 12 de diciembre de 2018 (rec. 4959/2017), o de 10 de diciembre de 2018 (rec. 234/2016).

En el caso concreto de Baleares la Ley 6/2017, de 31 de julio, de modificación de la Ley 8/2012, de 19 de julio, del Turismo, relativa a la comercialización de estancias turísticas en viviendas, abordó esta cuestión introduciendo notables limitaciones a la comercialización de estancias turísticas.

En principio, esta regulación hace viable exclusivamente el alquiler de la vivienda completa, y no en vano el art. 50.15 entiende que las estancias turísticas son incompatibles con la formalización de contratos por habitaciones o con la coincidencia en la misma vivienda de personas usuarias que hayan formalizado contratos diferentes, sin perjuicio de la regulación de estancias turísticas en habitaciones que se pueda establecer.

No obstante lo anterior, este mismo precepto en su punto 20 contempla la modalidad de alquiler de vivienda principal, que consiste en la comercialización llevada a cabo exclusivamente por personas físicas en una vivienda de su propiedad y que tenga la consideración de vivienda principal, independientemente de la tipología unifamiliar o plurifamiliar, por un plazo máximo de 60 días en un período de un año. En esta modalidad sí se permite la convivencia de las personas residentes en la vivienda con las personas usuarias, siempre que este hecho se indique claramente en toda la publicidad y el número total de personas no supere el número de plazas de la cédula de habitabilidad o título de habitabilidad análogo de la vivienda.

Desde el punto de vista urbanístico, el legislador balear pasa por encima de la distinción de uso y en una norma con rango de ley, como es la Ley del Turismo, expresamente admite que se pueden comercializar estancias turísticas de corta duración en viviendas de uso residencial, siempre que lleve a cabo esta comercialización la persona propietaria o se haga por 
medio de operadores o cualquiera de los canales de comercialización turística en los términos contemplados por el ordenamiento jurídico (art. 50.1). Eso sí, la Ley exige que las viviendas tengan cédula de habitabilidad en vigor, salvo las viviendas expresamente excluidas por normativa sectorial, por ejemplo, de patrimonio histórico (art. 50.2). También en este ámbito, se impide la comercialización de estancias turísticas en ninguna vivienda sobre la que haya recaído una sanción firme por infracción grave o muy grave de la legalidad urbanística, mientras no se restituya esta legalidad (art. 50.4). Asimismo, las viviendas de uso residencial sólo podrán comercializar estancias turísticas por el número máximo de plazas que permita la cédula de habitabilidad (art. 52.1).

En materia de recursos y acometidas, las viviendas residenciales objeto de comercialización turística tiene que acreditar la sostenibilidad mediante la obtención, previa a la comercialización, del certificado energético (art. 50.5), así como sistemas de control del consumo de agua y de contadores individuales de electricidad y gas (art. 50.6).

Un dato singular que afecta al Derecho de la competencia es el de la zonificación ${ }^{10}$. En este sentido a tenor de la Ley balear sólo se pueden presentar nuevas declaraciones responsables de inicio de actividad de comercialización de estancias turísticas en viviendas y, por lo tanto, llevar a cabo una nueva comercialización turística, si estas declaraciones se refieren a viviendas de uso residencial que estén ubicadas en las zonas declaradas aptas de manera expresa (art. 50.4).

En todos los casos, la presentación de la declaración responsable de inicio de actividad turística que se refiera a estancias turísticas llevadas a cabo en viviendas residenciales sometidas al régimen de propiedad horizontal, o a las de las tipologías que se determinen reglamentariamente, habilita para el ejercicio de la actividad por el plazo que se fije reglamentariamente y que, por defecto, es de cinco años desde la presentación a la Administración turística. Pasado el plazo establecido, se puede continuar con la comercialización turística sólo si se siguen cumpliendo todos los requisitos determinados legal o reglamentariamente, incluido que la zona siga siendo apta, por periodos prorrogables del mismo plazo.

Durante el mes anterior a la finalización de cada periodo, si la vivienda sigue cumpliendo todos los requerimientos determinados legal o reglamentariamente, el propietario de la vivienda, o el comercializador, puede presentar a la Administración turística una comunicación relativa al hecho 10 Sobre esta materia de la zonificación, véase Sola Teyssiere (2005). 
de que se prorroga el plazo de comercialización por el mismo período, que sigue cumpliendo los requerimientos normativos y que tiene el certificado del órgano gestor de plazas o de la Administración turística que acredita que puede disponer de manera temporal de las plazas por otro período. En caso de que se cumpla el plazo y no se haya producido esta comunicación o que la vivienda ya no cumpla los requerimientos normativos establecidos en aquel momento, incluidos los urbanísticos, tiene que cesar la actividad de comercialización de estancias turísticas, la vivienda tiene que pasar a situación de baja definitiva y las plazas tienen que retornar de manera automática a los organismos gestores de plazas o a la Administración turística.

Entre las prohibiciones la Ley balear impide la comercialización turística de vivienda residencial sometida o que haya sido sometida al régimen de protección oficial o a precio tasado (art. 50.8), o que se encuentre en suelo rústico protegido, salvo que los instrumentos de ordenación territorial establezcan lo contrario (art. 50.18).

En materia de seguridad la LTIB obliga al comercializador de estancias turísticas a remitir a la Dirección General de la Policía la identificación de los usuarios (art. 50.11), que a su vez tienen que cumplir los usos de convivencia y de orden público, así como las normas de régimen interno de la comunidad de propietarios en los casos de propiedad horizontal (art. 50.12).

En este ámbito del tipo de propiedad, este precepto contempla en su punto 7 la posibilidad de que la vivienda turística se halle en un edificio de propiedad tumbada u horizontal, si bien declara ilegal el uso turístico en los casos en que los estatutos de la comunidad de propietarios determinen que no es posible un uso para finalidades distintas a la vivienda residencial.

Baleares es el territorio que registra el mayor índice de intensidad turística del mundo. En 2017 visitaron las islas 16 millones de turistas, lo que supone que, si el índice medio de intensidad turística es de 100, Baleares registra $6.572^{\prime} 61^{11}$. Ello obliga a adoptar políticas activas de integración del elemento territorial y medio ambiental en el sector turístico. Incluso, siendo el alquiler vacacional uno de los factores impulsores de este índice de intensidad turística, la zonificación - directamente vinculada a la capacidad de carga de la población turística (LÓPEZ BONILLA; LÓPEZ BONILLA, 2008) -, deviene un factor clave en la ordenación turística.

En consonancia con lo que hemos dicho en relación a la capacidad de carga turística de un territorio, la Ley habilita a los Planes de Intervención 
en Ámbitos Turísticos (PIAT) y, si procede, los Planes Territoriales Insulares (PTI), a establecer la densidad global máxima de población, delimitar zonas y ámbitos turísticos y de protección, fijar el tamaño y las características, así como establecer parámetros mínimos o máximos de superficie, volumetría, edificabilidad y equipamientos. Pueden delimitar las zonas turísticas saturadas o maduras, de acuerdo con los criterios establecidos en esta ley. Asimismo, pueden señalar las excepciones que por la ubicación o las características especiales así lo aconsejen. También pueden determinar estos parámetros respecto a las zonas residenciales lindantes con las turísticas.

A lo que a nosotros interesa, a los PIAT corresponde establecer los criterios para la delimitación de las zonas aptas para la comercialización de estancias turísticas en viviendas de uso residencial. Sobre la base de estos criterios, los Ayuntamientos tienen que implantar las zonas aptas para la comercialización de estancias turísticas en viviendas residenciales, incorporando la delimitación al planeamiento urbanístico respectivo mediante la correspondiente documentación cartográfica ${ }^{12}$. Del mismo modo, los PIAT $\mathrm{y}$, si procede, los PTI, pueden determinar en cada isla el límite máximo de plazas turísticas en alojamientos turísticos y el límite máximo de plazas en viviendas residenciales susceptibles de ser comercializadas turísticamente, en función de los recursos insulares existentes, las infraestructuras, las densidades de población y otros parámetros relevantes de su ámbito. En este supuesto, las bolsas de plazas deben adaptarse a esta cifra ${ }^{13}$.

El art. 50.3 LTIB contempla la denominada zonificación del alquiler turístico, en la medida en que únicamente permite presentar nuevas declaraciones responsables de inicio de actividad de comercialización de estancias turísticas en viviendas $\mathrm{y}$, por lo tanto, llevar a cabo una nueva comercialización turística si estas declaraciones se refieren a viviendas de uso residencial que estén ubicadas en las zonas declaradas aptas de manera expresa, siguiendo el procedimiento previsto en el artículo 5, o delimitadas provisionalmente de acuerdo con lo que prevé el artículo 75 LTIB.

De acuerdo con el art. 75.2, tiene la consideración de zona apta para la comercialización de estancias turísticas en viviendas de uso residencial aquella en que, motivadamente, con las medidas correctoras que se puedan

12 De acuerdo con el dato positivo de la Ley, esta delimitación cartográfica no será considerada una modificación estructural del planeamiento.

13 Hasta que no se determine esta cifra o si no se considera necesario determinarla, el techo máximo de plazas por isla tiene que ser el determinado por las existentes legalmente más las que integren las bolsas gestionadas por los organismos gestores de plazas turísticas o las administraciones turísticas insulares, con las especificaciones previstas en el artículo 89 para la isla de Menorca. 
establecer y cumpliendo las previsiones establecidas legalmente o reglamentariamente en materia de vivienda, la Administración competente para llevar a cabo la zonificación considere que esta utilización extraordinaria de las viviendas residenciales resulta compatible con el uso ordinario de vivienda que las caracteriza.

En su punto siguiente, este mismo precepto permite que, con carácter provisional, mientras los consejos insulares no desarrollen mediante PIAT o, si procede mediante PTI, la delimitación de las zonas aptas para la comercialización de estancias turísticas en viviendas de uso residencial, los entes insulares puedan declarar y delimitar provisionalmente mediante acuerdo del pleno las zonas aptas para la comercialización de estancias turísticas en viviendas de uso residencial, que pueden diferenciar por tipologías edificatorias. Este acuerdo se tiene que publicar en el Boletín Oficial de les Illes Balears y regirá hasta que los Ayuntamientos establezcan la delimitación respectiva en el planeamiento urbanístico municipal.

\subsection{Actuaciones en el fondo marino}

La protección de ecosistemas marinos se convierte en un elemento de primer orden para la vida en el fondo del mar, fundamentalmente la oxigenación del agua, de manera que automáticamente pasa a formar parte de las limitaciones al turismo.

En efecto el atraque de embarcaciones de recreo en el fondo del mar, por el arrastre que supone la fijación del ancla, perjudica seriamente la preservación y el crecimiento de praderas de posidonia.

En España y de acuerdo con la legislación estatal básica ${ }^{14}$, la Comunidad Autónoma de las Islas Baleares aprobó ${ }^{15}$ el Decreto 25/2018 de 27 de julio, sobre la conservación de la Posidonia oceánica en las Islas Baleares, que protege un espacio de 650.000 metros cuadrados de fondo marino poblado por esta especie marina.

Este Decreto prevé la delimitación cartográfica y catalogación de las praderas de posidonia (art. 3), así como la regulación del fondeo de embarcaciones, totalmente prohibido sobre praderas de posidonia (art. 7).

El artículo 12 crea un fondo, llamado Fondo Posidonia, que se nutrirá

14 La Ley 42/2007, de 13 de diciembre, del Patrimonio Natural y de la Biodiversidad; la Ley 41/2010, de 29 de diciembre, de Protección del Medio Marino, y el Real Decreto 139/2011, de 4 de febrero, para el desarrollo del Listado de Especies Silvestres en Régimen de Protección Especial y del Catálogo Español de Especies Amenazadas.

15 Previo dictamen 64/2018, del Consejo Consultivo de las Islas Baleares, aprobado en sesión de fecha 11 de julio de 2018.

Veredas do Direito, Belo Horizonte, ·v.17 ·n.39 · p.11-38 $\cdot$ Setembro/Dezembro de 2020 
de las aportaciones que la Comunidad Autónoma de las Illes Balears, otras administraciones, empresas, asociaciones y otras, así como de las medidas compensatorias de actuaciones que afecten al hábitat y especie. Se indica que la gestión del fondo corresponde a la Consejería de Media Ambiente, Agricultura y Pesca, directamente o a través del ente instrumental al que se atribuya esta competencia.

Por último este Decreto contempla un régimen sancionador para aquellas embarcaciones que fondeen sobre praderas de posidonia, así como cualquier alteración significativa de la misma, entendida como cualquier afectación, con resultado de destrucción o muerte, de la Posidonia oceánica como especie o hábitat, mediante la ocupación perenne o temporal de su espacio, la roturación, la tala, el arranque, la desestabilización de su sustrato $\mathrm{u}$ otras acciones que supongan un deterioro de sus condiciones naturales.

El Decreto aborda en su Anexo II una cuestión polémica, como es la retirada de los restos de posidonia varados en la orilla. La norma defiende las bondades de tales restos para la conservación de las playas y la generación de sedimentos. Sin embargo esta circunstancia debe ponerse en relación a la dificultad funcional que restos de algas muertas y putrefactas, con un fuerte hedor, provoca en las playas de uno de los mayores destinos turísticos mundiales.

\subsection{Limitación de accesos a los espacios públicos}

Otra forma de limitar la presencia de visitantes y turistas en determinadas zonas consiste en el establecimiento de un sistema de cupos.

Tal es el caso de la Playa lucense de Las Catedrales (Ribadeo), que cuenta con un sistema de autorización para su acceso y visita, a través de una página web, que únicamente habilita 4.812 visitas diarias en Semana Santa y de julio a septiembre. Esta restricción se fundamenta en el problema de saturación que viene sufriendo en los últimos tiempos el arenal gallego, que puede suponer un riesgo para una zona que, además del turístico, tiene un gran interés natural. El objetivo de la Administración autonómica consiste en preservar el paisaje, combinar su aprovechamiento turístico y medioambiental, promocionar los medios de transporte alternativo y fomentar el conocimiento de su biodiversidad, entre otras.

En aplicación de la Ley 9/2001, de Conservación de la Naturaleza, quien ignore el veto y decida transitar por las sendas peatonales existentes podrá ser sancionado con multas de 600 a 6.000 euros. La medida supone 
atender las recomendaciones de geólogos y expertos de la Universidad de La Coruña, que coinciden en advertir que la parte superior de los acantilados de Las Catedrales son un espacio especialmente sensible, con hábitats prioritarios en la Unión Europea que hasta ahora sistemáticamente eran pisoteados por miles de visitantes. Además, con ello se degradaba el manto vegetal, propiciando las filtraciones de aguas pluviales que erosionaban cuevas, grutas, cornisas y salientes, provocando desprendimientos.

No muy distinto es el caso de las Islas Cíes, en la misma Comunidad Autónoma de Galicia. Por razones medio ambientales y de saturación turística, fundamentalmente embarcaciones, el Plan rector de usos y gestión del Parque Nacional Marítimo-Terrestre das Illas Atlánticas de Galicia establece un cupo de visitantes para la isla de Ons (1.800 personas por día) y las Islas Cíes (2.800 visitantes diarios).

La limitación del acceso a la Isla de Ons ha sido una consecuencia obligada después de la limitación a las Islas Cíes, por cuanto la primera se convirtió en la alternativa libre a las restricciones a las Cíes, desplazando la saturación de unas islas a otras.

En las Islas Canarias sucede otro tanto con la Isla de Lobos, considerada Parque Natural y en la que el Plan Rector de Uso y Gestión limita a 200 el número de visitantes, al tiempo que prohíbe la realización de acampadas.

En Baleares la isla de Cabrera, declarada Parque Nacional Marítimo-Terrestre por Ley 14/1991, de 29 de abril, cuenta con un Plan de Ordenación de Recursos Naturales (aprobado por Real Decreto 1431/1992, de 27 de noviembre, por el cual se aprueba el Plan Rector de los Recursos Naturales del Parque nacional marítimo-terrestre del archipiélago de Cabrera), y un Plan Rector de Uso y Gestión (aprobado por Decreto 58/2006 de 1 de julio).

Existen actividades totalmente permitidas (la observación de la fauna y la flora, la realización de fotografías no profesionales sin salir de los itinerarios, así como todas aquéllas que no alteren los valores paisajísticos, naturales y culturales del Parque), actividades que requieren autorización previa (la actividad de profesionales de filmación, fotografía, vídeo, etc; buceo, la navegación y fondeo, los actos de carácter multitudinario, toda actividad comercial que se tenga que desarrollar en establecimiento fijo, y la actuación como guía interpretador, guía turístico o informador en el interior del Parque). Por último existen actividades declaradas expresamente prohibidas: tirar residuos y desperdicios, extraer cualquier tipo de material geológico, extraer o alterar cualquier objeto arqueológico, recoger 
cualquier tipo de material, vivo o inerte, soltar, sembrar, trasplantar especies animales o vegetales, encender fuego y fumar, atracar embarcaciones fuera de las zonas expresamente autorizadas, acampar en todo el territorio del Parque Nacional, hacer bullicio, llevar a cabo cualquier tipo de actividad cinegética, acceder en el suelo en cualquier punto diferente de las tenazas del puerto de Cabrera, circular fuera de las pistas y caminos, bucear en apnea durante los meses de mayo y junio en las zonas de costa donde la especie Scyllarides latus hace su puesta, la pesca deportiva, o volar drones.

De manera más específica existen restricciones y cupos para el acceso a la Cueva de Altamira, donde el Patronato del Museo Nacional y Centro de Investigación de Altamira hace suyas las recomendaciones de la Comisión de Seguimiento del Plan de Conservación Preventiva de la cueva y mantiene las visitas a la misma de manera controlada y limitada con el acceso de cinco personas y dos guías a la semana. En este sentido y aunque la causa principal del deterioro de las pinturas consiste en la infiltración de agua por lavado, la presencia de personas (emisión de CO2) ha contribuido al deterioro por cuanto la cueva ha estado recibiendo 30.000 personas al año en 1952, 60.000 en 1957, y hasta 175.000 en 1973, debiendo restar cerrada al público entre 2002 y 2005.

La limitación del acceso a espacios públicos no es nueva en Brasil. Entornos territoriales con un alto nivel paisajístico como las Islas de Fernando de Noronha (Pernambuco) o Bonito (Mato Grosso del Sur) son un ejemplo de limitación de la presencia humana salvo excepciones para fines científicos. Asimismo y desde 1976 Brasil viene introduciendo restricciones por ejemplo a la Isla de Paquetá (Río de Janeiro).

Administrativamente la isla constituye un barrio del municipio de Río de Janeiro, de manera que el art. 180 del Decreto No. 322 de 1976 prohíbe, entre otros extremos, la apertura de nuevos espacios públicos en vías interiores de agrupación de edificios, la tala de árboles sin previa autorización municipal, o el tránsito de vehículos motorizados de cualquier especie y para cualquier fin, excepto de los indispensables para el servicio público.

A mayor abundamiento y a raíz del Decreto 17.555/1999, la isla de Paquetá se transformó en un área de preservación ambiental y cultural (APAC), concebido como un instrumento urbano municipal que persigue preservar las estructuras físicas tradicionales como edificios y otras referencias culturales para la ciudad: leyendas, festivales tradicionales... 


\section{CONCLUSIONES}

El fomento del turismo, con una actividad concurrente entre todos los niveles de Administración, ha dado lugar a una masificación de espacios y territorios turísticos, generando una serie de distorsiones como la dificultad de acceso a la vivienda, la expulsión de la población residente o la generación de conflictos sociales y turismo fobia. La masificación ha sido el resultado de un abaratamiento de los costes y del mayor tiempo de ocio disponible, pero muy especialmente se explica asimismo por las políticas públicas de fomento del turismo a través de fórmulas de desestacionalización (turismo de congresos, deportivo, turismo rural...).

La consecuencia de lo anterior ha sido el peligro y deterioro de la variable ambiental, de manera que el turismo ha hecho mella en el consumo de territorio, especialmente la costa y el litoral, así como en los recursos naturales (disponibilidades hídricas, energía, generación de residuos...).

Estas derivaciones de la masificación turística han llevado al legislador a articular la política de turismo (hasta entonces, exclusivamente económica) en clave medio ambiental, de manera que la sostenibilidad se ha erigido como un elemento transversal del turismo. Este cambio de las políticas públicas en materia de turismo ha sorprendido a los operadores turísticos (fundamentalmente los propietarios de alojamientos hoteleros y extra hoteleros), que ven peligrar su actividad como consecuencia de las limitaciones introducidas por las Administraciones.

No en vano en los últimos tiempos el legislador ha arbitrado medidas reguladoras del turismo, como la tasa turística por pernoctación, el establecimiento de la capacidad de carga de un territorio, la limitación directa y frontal del alquiler turístico, la conservación del fondo marino, o los accesos a espacios públicos a través de sistemas de cupos. Son todas ellas experiencias que se conocen tanto en Brasil como en España, y que no impiden que se vayan adaptando a los cambios sociales que se vayan experimentando.

En cualquier caso son éstas medidas revolucionarias, nunca previstas años atrás, pero que se han impuesto por imperiosa necesidad medio ambiental. A los operadores jurídicos nos corresponde hacer un seguimiento puntual de la evolución que experimente el binomio turismo y medio ambiente al objeto de proponer medidas correctoras y reformas normativas. 


\section{REFERENCIAS}

BAUZÁ MARTORELL, F. J. Public Law of Tourism. 4. ed. Palma: Universidad de las Islas Baleares, 2017.

BAUZÁ MARTORELL, F. J. Islas Baleares. In: AECIT - ASOCIACIÓN ESPAÑOLA DE EXPERTOS CIENTÍFICOS EN TURISMO. La actividad turística española en 2018. Madrid: Síntesis, 2019.

BAUZÁ MARTORELL, F. J. Hacia una legislación básica en materia de turismo. A propósito de las centrales electrónicas de reservas turísticas. Diario La Ley, 27 mayo 2014.

BAUZÁ MARTORELL, F. J. Intervención administrativa en la vivienda turística vacacional. Revista Española de Derecho Administrativo, n. 189, p. 313-346, ene./mar. 2018.

BAUZÁ MARTORELL, F. J. Planeamiento urbanístico y turismo. A propósito de la zonificación del alquiler turístico. Práctica Urbanística, n. $152,2018$.

BLASCO ESTEVE, A. La planificación territorial de las zonas turísticas en España. Revista de Derecho Urbanístico y Medio Ambiente, n. 262, dic. 2010.

ENCARNACIÓN, A. M.; BALOP, A. B.; GOLOBARDES, M. A. La regulación del alojamiento colaborativo: viviendas de uso turístico y alquiler de corta estancia en el Derecho español. Madrid: Cizur Menor, 2018.

FERNÁNDEZ, T. R. El desconcertante presente y el imprevisible y preocupante futuro del Derecho urbanístico español. Revista Española de Derecho Administrativo, n. 94, p. 189-201, 1997.

FERNÁNDEZ GONZÁLEZ, C. El impuesto balear de estancias turísticas. Palma: Lleonard Muntaner, 2017.

FLAQUER RIUTORD, J. Algunos problemas jurídicos derivados de las nuevas formas de comercialización hotelera a través de canales electrónicos. Revista Aranzadi de Derecho y Nuevas Tecnologías, n. 37, p. 119-133, 2015.

FLECHA BARRIO, M. D. et al. El papel de las OTAs en el proceso de 
distribución de las cadenas hoteleras españolas. Esic Market Economics and Business Journal, v. 47, n. 3, p. 479-504, sep./dic. 2016.

GARCÍA SAURA, P. J. Viviendas de uso turístico y plataformas colaborativas en España: aproximación al régimen jurídico. Madrid: Dykinson, 2019.

HUETE, R.; MANTECÓN, A. El auge de la turismofobia ¿hipótesis de investigación o ruido ideológico? Pasos: Revista de Turismo y Patrimonio Cultural, v. 16, n. 1, p. 9-19, 2018.

LÓPEZ BONILLA, J. M.; LÓPEZ BONILLA, L. M. La capacidad de carga turística: revisión crítica de un instrumento de medida de sostenibilidad. El Periplo Sustentable, n. 15, p. 123-150, 2008.

MARTÍNEZ NADAL, A (Dir) Big data, cloud computing y otros retos jurídicos planteados por las tecnologías emergentes. Madrid: Cizur Menor, 2019.

MARTÍNEZ NADAL, A. Publicación en páginas web de valoraciones falsas con incidencia en la reputación digital de los empresarios de alojamiento: ¿una práctica desleal? Revista de Derecho Mercantil, n. 297, p. 139-169, 2015.

MILANO, C. Overtourism, malestar social y turismofobia. Un debate controvertido. Pasos: Revista de Turismo y Patrimonio Cultural, v. 16, n. 3, p. 551-564, 2018.

MUNAR BERNAT, P. A. La actividad de información turística. Los guías de turismo. In: MARTÍNEZ NADAL, A.; MUNAR BERNAT, P. A.; VERDERA IZQUIERDO, B. (Coords.) Derecho privado del turismo: estudio jurisprudencial. Madrir: Cizur Menor, 2008. p. 301-306.

NIETO, A. Derecho Administrativo Sancionador. 5. ed. Madrid: Tecnos, 2012.

SALOM PARETS, A. La capacidad de carga "conditio iuris" en la normativa territorial y turística. Revista de Derecho Urbanístico y Medio Ambiente, n. 313, p. 39-63, abr./mayo 2017.

SOLA TEYSSIERE, J. Ordenación territorial y urbanistica de las zonas turísticas. Sevilla: Instituto Andaluz de Administración Pública, 2005. 
Artículo recibido el: 28/11/2019.

Artículo aceptado el: 19/10/2020.

\section{Cómo citar este artículo (ABNT):}

BAZUÁ MARTORELL, F. J. Políticas públicas de turismo sostenible: perspectiva hispano brasileña. Veredas do Direito, Belo Horizonte, v. 17, n. 39, p. 11-38, sep./dic. 2020. Disponible en: http://www.domhelder.edu. br/revista/index.php/veredas/article/view/1726. Acceso: día del mes. año. 